Research Article

\title{
Poverty of Energy and Its Impact on Living Standards in Ethiopia
}

\author{
Elias Mandefro Getie iD \\ Bahir Dar University, Bahir Dar Institute of Technology, Bahir Dar, Ethiopia \\ Correspondence should be addressed to Elias Mandefro Getie; eliasmandefro01@gmail.com
}

Received 8 May 2020; Revised 22 June 2020; Accepted 23 June 2020; Published 23 July 2020

Academic Editor: Fabio Massaro

Copyright (C) 2020 Elias Mandefro Getie. This is an open access article distributed under the Creative Commons Attribution License, which permits unrestricted use, distribution, and reproduction in any medium, provided the original work is properly cited.

\begin{abstract}
Energy is the backbone of the economic development of a country. Ethiopia has bulk energy resource potential, and the effect of energy poverty on well-being, physical health, agriculture automation, education system, industries, and ability to prosper is valuable. A large proportion of the population living in Ethiopia has no electricity access. Among more than 110 million people living in Ethiopia, $46 \%$ only use electric energy for day-to-day activities like food preparation and other tasks. In the rural area of the country, where $80 \%$ of the population lives, people have no sustainable energy supply. The rural electrification needs special mechanisms to enhance the living standards of the people by opening opportunities for electric power infrastructures. The sustainable development of the country will be achieved when citizens are enabled to live up to the standard of living as humans. This paper investigates energy poverty in Ethiopia and its impact on the living standards of the people, like human resource development, health of individuals, and automation of agriculture, for the purpose of upgrading individual's lifestyle in the country.
\end{abstract}

\section{Introduction}

The development of a country depends on the consumption of electric power. The quality of life depends on the electric power infrastructure. Ethiopia is a country which has bulk electric power resource potential in nonrenewable and renewable energy resources. On the other hand, 55\% of the population in the country have no electrical infrastructure and use wood for food preparation [1]. The electric power facility makes it simple for rural people to perform different tasks. Most people living in the rural area use fuel for lighting and wood/charcoal for food preparation due to energy poverty.

The poverty of energy can be defined as "the absence of sufficient choice in accessing affordable, adequate, highquality, reliable, safe and environmentally friendly energy services to improve economic and human development" [2]. Energy poverty, in short, can be expressed as the "inability to cook with modern cooking fuels and the lack of a bare minimum of electric lighting to read or for other household and productive activities at sunset" [2]. One of the development goals of Ethiopia is facilitating electric power for the rural and urban areas under the rural electrification program to improve the lifestyle of the people [3].

The energy poverty impacts individuals of the society, regardless of their income. Educational sectors need electric power to deliver courses in a better manner. Students of the rural area want to read different materials, including class activities on the night. Even the current situation of COVID-19 interrupts the education system while the Ministry of Education announces programs to give lectures using different television channels of the country. This is unbelievable and did not consider the real situation of the rural area of the country. Most children living in the rural part of Ethiopia are unable to attend the courses delivered in the live TV programs, which has great impact on quality of education due to energy poverty. The development of a country is measured by the human resource development, but in Ethiopia most infrastructures ignore the major part of its population whose contribution for the country is invaluable.

The poverty of energy has also strong impact on the health of individuals. Women who use wood and charcoal for food preparation are exposed to different respiratory 
diseases as compared to those who use electric energy. The information and awareness among the society of different pandemic diseases like COVID-19 are not enough. The lack of electric power in individuals' homes has a big effect on ventilation and comfort of homes. The indoor pollution in homes will continue as long as the poverty of energy is not minimized.

The automation of agriculture requires electric power starting from land preparation to the final cultivation of products. Farmers of the rural area produce tomatoes, carrots, and different fruits which must be preserved in fridges to stay in normal conditions, but this is not practical due to poverty of energy [4]. The manual water feeding in irrigation canals reduce the efficiency of products and there is a high loss of nutrients. Automatic irrigation system, including modern irrigation canals, is required to improve the output of irrigation system and to make the agriculture life simple and moderate [4]. The water flowing out of irrigation canals can solve the energy poverty of the society if it is used for electric power generation before using it for irrigation.

Generally, the impact of energy poverty on human resource development, health, and agriculture automation shall be given high attention from the government of Ethiopia, private sectors, and educated persons so as to mitigate those fundamental problems of the country.

The energy resource potential of the country is indicated in Figure 1. The country has bulk energy potential in renewable and nonrenewable energy resources, but still Ethiopia faces poverty of energy. The wind and solar power potential of the country gives the citizens of rural area more access to those free and equally available natural resources, but still less than $1 \%$ of the potential is used [5]. The hydropower generation capacity of Ethiopia is around $45 \mathrm{GW}$, but still only $6 \%$ of the potential is used [6]. The agricultural waste and wood consumption for different purpose are high, which leads to high deforestation and global warming. The highest used resources are wood and agricultural wastes with $57 \%$ and $34 \%$ of the potential that the country has [6]. The natural energy potential, the current consumption as percent, and the types of energy resources are shown in Table 1 and Figure 1 in detail.

\section{Survey of the Literature}

The papers that addressed the impact of energy on humans, economic development, and social development were thoroughly reviewed.

Hou et al. [7] conducted a study on the economic growth due to electricity consumption in China using electricity demand forecasting and multivariable cointegration analysis, indicating the real GDP of the country related directly to the electricity price, consumption, and structure of the economy. The price of electricity, GDP, and the electricity consumption of large industries were studied in detail in terms of their relationship with China's development. This research is important as it shows how much electrical energy influences the development of any country in varying forms.

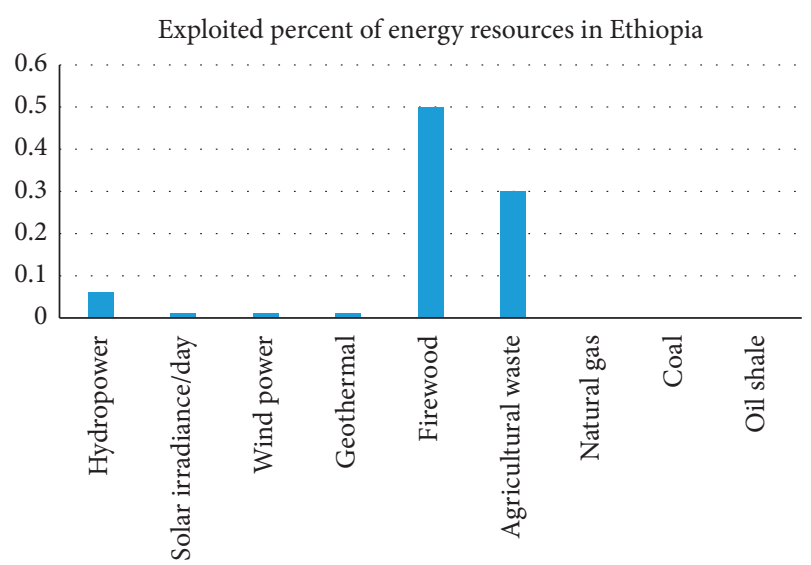

Figure 1: Percentage of energy resources used in Ethiopia.

TABLE 1: Energy resource potential and percentage of its potential usage in Ethiopia.

\begin{tabular}{lcc}
\hline Resource & Exploitable reserve & $\begin{array}{c}\text { Exploited percent } \\
(\%)\end{array}$ \\
\hline Hydropower & $45000 \mathrm{MW}$ & 0.06 \\
Solar irradiance & $4-6 \mathrm{kWh} / \mathrm{m}^{2} /$ day & 0.01 \\
Wind: power & $100 \mathrm{GW}$ & 0.01 \\
Geothermal & $<10,000 \mathrm{MW}$ & 0.01 \\
Firewood & 1120 million tons & 50 \\
Agricultural & $15-20$ million tons & 30 \\
waste & 113 billion cubic & 0 \\
Natural gas & meters & 0 \\
Coal & 300 million tons & 0 \\
Oil shale & 253 million tons & \\
\hline
\end{tabular}

Frias et al. [8] proposed the renewable energy impact on economy of the Spanish market of electricity by calculating carbon emission and operation cost of fuel based generation systems, and finally the price of electricity and margins of operation of power plants in Spain were also discussed. According to this research, the penetration of renewable energy resources in power system will increase and find solutions for electric demand.

$\mathrm{Xu}$ and Singh [9] suggested the reliability of the distribution system and the improvement of economy with different energy storage control mechanisms by integrating these mechanisms with the distribution systems. The controlling mechanisms significantly impacted the improvement of economy and reliability during penetration of energy storage systems to distribution networks. This paper indicated that using an energy storage system with integration of existing network can maximize reliability and economic development of a country.

Rubio and Robaina [10] proposed the impact of an investment economy in the electricity sector analyzed using technological and hybrid general equilibrium of Spain. The effect of the evolution of new technology and investments on the electric sector and economy of Spain was analyzed. The insufficient investment of renewable energy and high price for $\mathrm{CO}_{2}$ emission made the impact more valuable. The reduction of emission of $\mathrm{CO}_{2}$ led to the 
increment of GDP, mitigating the increment of electricity price in Spain.

Mouse et al. [11] assessed the economic impact and analysis of feasibility of renewable energy systems at a microgrid in Somaliland to mitigate the social and economic challenges of the country by integrating renewable energy sources at a microgrid level in distribution and transmission systems. The shortage of electric energy and loss of power during transmission also constitute another obstacle that needs to be considered. The reliance of urban and rural community on biomass energy makes it difficult to have a sustainable energy resource due to the degradation of the biomass in the rural community of Somaliland. This research clearly shows the importance of shifting energy resource types from ordinary and nonrenewable to renewable and green energy resources.

\section{Methodology}

The data for shortage of energy were collected from the community living in the rural and urban areas through direct interviews. Data from the central statistical agency of the country were analyzed in terms of its impact on households, education, health, and agricultural development. From the collected sample data, the energy poverty effect was clearly described and compared in the rural and urban areas of Ethiopia using statistical data analysis, basically quantitative data analysis including survey data.

\section{Assessing Poverty of Energy and Its Impact}

Poverty of energy is a multidimensional concept which includes life expectancy, quality of housing, literacy, calorific intake, and energy access from other factors. The lack of electricity access and dependence on traditional cooking fuels, i.e., wood, charcoal, and animal dung, can express poverty of energy in the society [12]. The complex causes of poverty of energy may be lack of installation income, identifying the available energy resources in the rural area of the country, awareness of the significance of using electric energy, and the high cost of energy to be paid for the utility. Estimating the poverty of energy starts from the budget share households and industry spending on fuels and electricity. In terms of time management, people using wood in households for food preparation spend their time and energy collecting woods mostly far from their local homes. Energy development index measures the satisfactions of people living in the rural area in terms of electric energy supply, which shows the poverty of energy in developing countries [13].

The quality of living is the standard of welfare available to the community. It focuses on materials and services given to people and the resources they have. It includes different factors such as poverty rate, income, affordability and quality of housing, inflation rate, affordable access to healthcare, availability and quality of education, and life expectancy [14]. One measure of the quality of living is human development index which has three main components: expectancy of life, level of education, and a decent standard of living measured by per capita income [3]. The availability and consumption of goods and services are affected directly or indirectly by the access of electric energy and this affects living standard [2].

The energy infrastructure of Ethiopia compared to its total population is still not satisfactory. It needs new strategies to offer energy opportunities for all citizens in the country using the bulk energy resources distributed in different parts of the country. Figure 2 clearly shows that, from a population of 110 million in Ethiopia, only $45 \%$ have access to electric energy [6], and 55\% of the population still uses the traditional energy resources which have side effects on health, education, and agriculture automation. The living standard continues with traditional experiences with no clean water, moderate cooking system, moderate preservation mechanisms, including food in households and medicines in clinics, and information sharing using cell phones due to lack of electric power. The quality of education brings the development of quality systems which easily and smartly serve the society. This will be achieved if the infrastructures are facilitated up to the standard of the education level. The energy poverty affects the overall living standard of the population in the country. The objectives of modern technologies include making life on Earth simpler, productive, healthy, skillful, and knowledgeable; solving problems; encouraging creativity; and offering great contribution to the society and the world.

\section{Poverty of Energy Manifestation in Ethiopia}

The impacts of energy poverty on individual households, health centers, and educational institutions and industries in Ethiopia are clearly stated in this section. The selection of these areas is due to the direct influence of energy poverty on them; the primary energy of those target areas mainly relies on fuel woods, charcoal, and animal dung, some of the points of concern used to analyze the poverty of energy. They also demonstrate how low access to and high cost of energy can bring poverty of energy in the country. Safe drinking water is the issue of most rural Ethiopians and is still not satisfied, as they depend on unpurified water from flowing rivers, springs, and ponds.

5.1. Poverty of Energy in Households. Ethiopia is a country in which $80 \%$ of the population lives in the rural area. In the selected 10,368 householders from the rural area, whose data were collected from the central statistical agency, the major energy sources were as follows: $85 \%$ firewood, $22 \%$ charcoal and animal dung, and $14 \%$ gas for lighting. The major energy source of rural households is firewood whereas in cities charcoal is also used next to electric power. There is no rural area of Ethiopia using electric power for food preparation, and another function may be lighting in some areas near to hospitals, schools, and industries. The rate of energy consumption of rural part of Ethiopia is shown in Figure 3.

5.2. Poverty of Energy in Schools. Most schools in rural area have no electric energy source. Students from the rural area did not take ICT classes in practice [15]. This makes a 


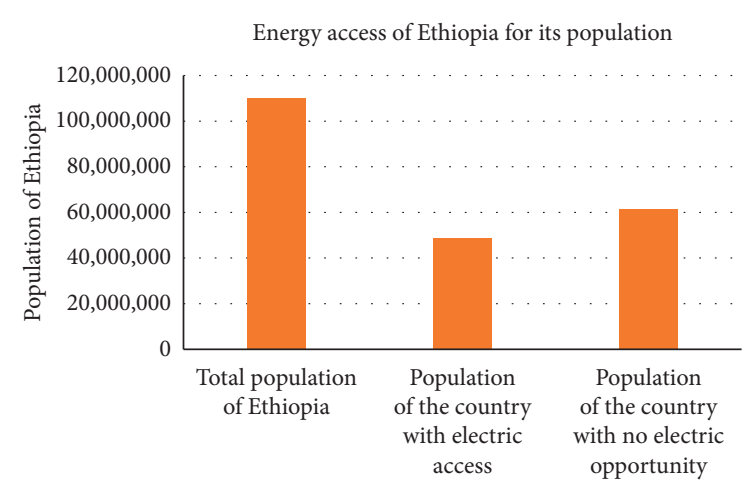

Figure 2: Energy access of Ethiopia.

Energy consumption of rural Ethiopia

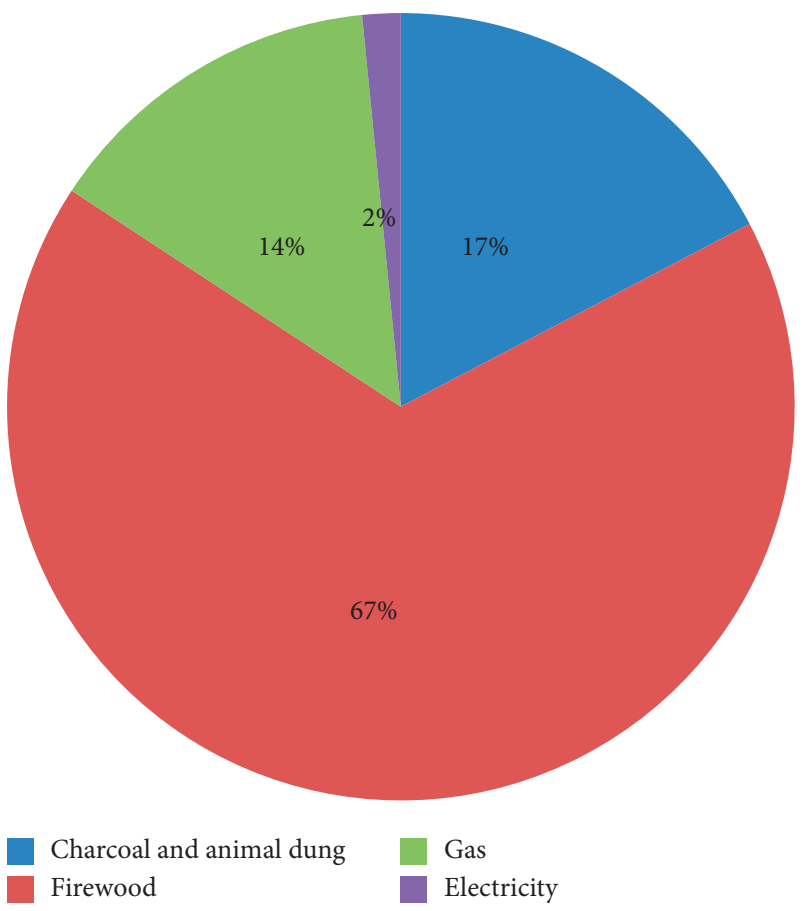

FIgURE 3: Energy consumption of rural area in Ethiopia.

difference in the quality of education as well as in knowledge of students. Teaching by other alternative mechanisms is not possible due to requirement of energy. Currently, the unexpected pandemic disease is also one major indicator of poverty of energy that challenges continuing education online. From the data collected by taking samples of 970 households from the rural community through interviews, it was found that almost all students from the community read by using gas for lighting if not at the day time when they have no work to help their family in.

5.3. Poverty of Energy in Health Centers. Health centers in rural Ethiopia are unable to use modern health instruments due to unavailability of electric energy sources, so most health services give treatment by asking about the patient history and the pains reported by the individual. In general, energy poverty has great effect on personal hygiene, health problems, personal development, and awareness of information. The human resource development can be maintained when the health of individuals is in a better condition. Women use firewood for any task that needs heat energy and are exposed to blindness due to the smoke of firewood for a long time. Collecting firewood from a distance is also another challenge for rural communities with no proper transportation to home.

5.4. Poverty of Energy in Agriculture. Agriculture is the base for Ethiopians to survive from day to day. The product of agriculture and its variety are good in rural areas even though there is human energy wastage and it is not simple to work [16]. Until now, agrarian work is very complex, even if the product is not sufficient. The irrigation system needs to be modernized, and the fertility of the soil also needs to be maintained. In agriculture, the contribution of energy is invaluable. Using artificial light in most rural and urban areas can irrigate vegetables and solve the problem of food variety. Energy poverty mainly affects agriculture, which directly affects the health of individuals.

\section{Energy Poverty Implications for Living Standard}

Energy poverty directly affects civilization of people lifestyle. The economic development of individual's life strongly depends on energy. It targets the welfare level available to groups or individuals. The standard of living is influenced by the sustainable and adequate energy access. In rural parts of Ethiopia, energy poverty highly affects economic and personal development which are key points for a country's development [17]. The efficient lighting system in urban areas enables students to read at any time without waiting for sunlight, whereas in rural Ethiopia this is impossible. Country development is determined by the energy consumption of individuals, industries, and organizations which create job opportunities. The access to energy has an unlimited contribution to education; on the other hand, the use of firewood and charcoal has significant impact on health [14]. Energy has a direct impact on health, education, agriculture, and job opportunities. The flowchart in Figure 4 shows the relationship of energy with economy and interdependence of human development.

\section{Poverty of Energy and Policy Measures}

The impact of energy poverty on living standard, especially in education, health, and agriculture is discussed in this paper; it is important to take measures against energy poverty. Ethiopia is a country which has low income and there is a difficulty in improving the lifestyle of people living in the rural area as shown in Figure 5 which depicts women collecting firewood. Accordingly, the government shall take some of the following measurements. 


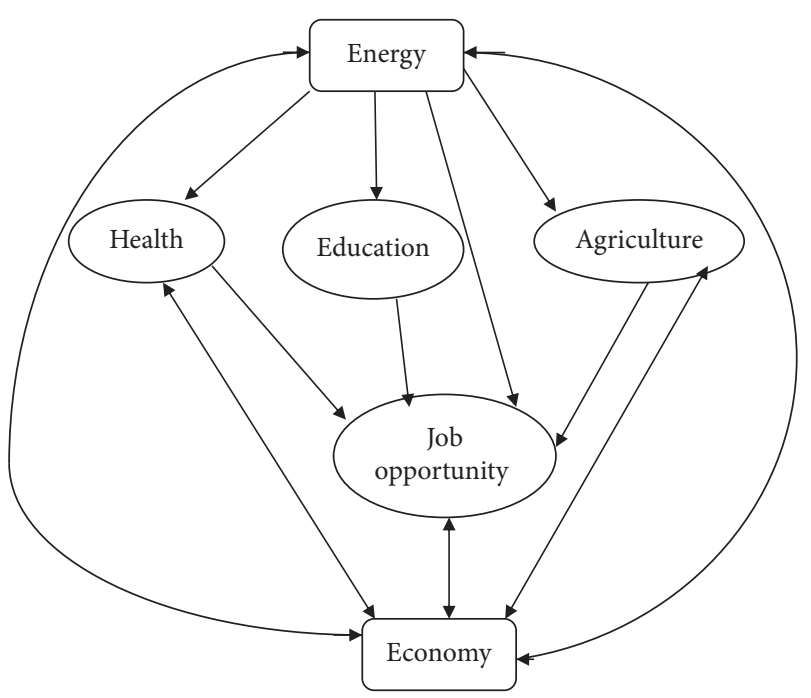

FIgURE 4: Relationship of energy with economy.

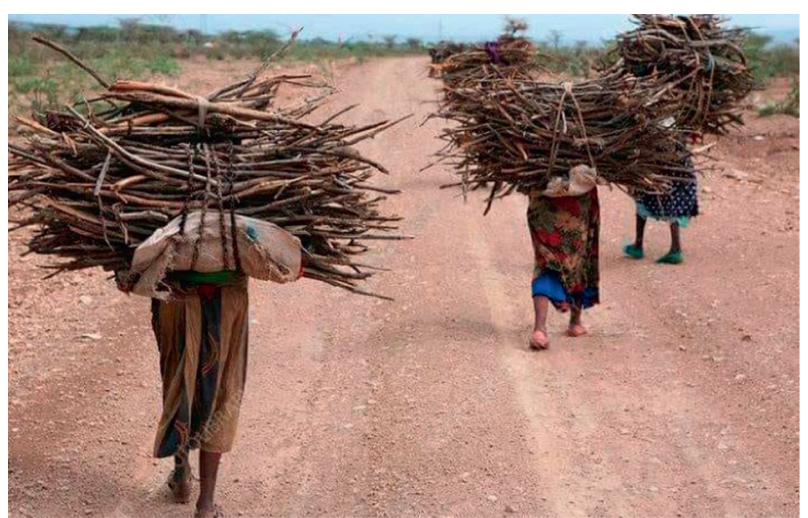

FIGURE 5: Effect of energy poverty in rural community in Ethiopia.

7.1. Shifting Energy Polices to the Use of Renewable Energy Sources Such as Solar Power, Wind Power, Tidal Power, and Hydropower. The potential of Ethiopia to use renewable energy resources needs special focus to change its economy and the living standard of its citizens. The geographic nature of Ethiopia varies, and the potential of generating hydropower, solar power, wind power, and others is also geographically dependent like the Renaissance Dam of Ethiopia which will eliminate the shortage of electricity when it starts power generation. The government shall motivate the use of renewable energy and allow investors to generate and sell it for citizens with proper price.

\subsection{Motivating Private Sectors to Generate and Supply Electric} Energy from Alternative Energy Sources. Constructing gridconnected microgrids and off-grid electric generation systems by mobilizing and supporting the private sectors enables mitigating poverty of energy in the country as a whole by sharing investment costs of the government. This again creates job opportunities in the country, which minimizes the challenge of employing graduates in different professions.
7.3. Clearly Identifying the Energy Potential of the Country and Creating Awareness among Investors. The energy potential of the country can enable the use of electric energy by the whole population of Ethiopia, but in reality the percentage of electricity usage is not the same as the potential of the country. The specific sites and the corresponding energy potential of the country should be clearly identified and advertised for attraction of investors to existence of sufficient energy resources in specific areas of the country.

7.4. Promoting the Use of Other Energy Types out of Hydropower. The electric energy of Ethiopia is dependent on hydropower untill now. This requires a high initial cost for construction of dams, whereas solar and wind power installation is not costly as compared to hydropower. Using other alternative energy resources eliminates deformation due to land and other requirements for dam construction.

7.5. Educating Consumers about the Use of Electric Equipment for Cooking and Other Operations. Customers need to use electricity for different tasks to make living style simple and save the time spent on wood collection. The impact of global warming and deforestation can be minimized by creating awareness of the contribution of electricity to various activities.

7.6. Minimizing the Service Cost and Maximizing the Facilities for Investors. The government is expected to facilitate logistics and facilities required by investors in a legal way. The service cost before installing any generation system in the country shall be optimum and properly used for its objective during service cost payment.

7.7. Increasing the Participation of Private Sectors in Energy Policy and Preparing Funding Process from Government and Private Business Sectors. The participation of private sectors in energy generation and utilization plays great role in the sustainable development of the country. The government shall allow the implementation of electrification programs which can address the shortage of electricity.

7.8. Promoting and Guaranteeing Microfinance Institutions to Give Funds for Solar Power Installation in the Rural Community with Long-Term Payment. Finance access should be enabled for all economic classes of the population. The establishment of microfinance helps not only in energy investment, but also in fighting poverty of the country by creating job opportunities for those who have new business ideas, projects, research, innovation, and others.

7.9. Finding Funds from International Organizations to Subsidize the Basic Energy Requirements. Funding policy should be established, and funding should be obtained from international organizations through submitting outstanding project proposals in the area of rural electrification using renewable energy resources. The resources available in the 
country and areas of installation should be clearly addressed to funding organizations through expert teams.

\section{Conclusion}

Electrical energy is the core of sustainable development and reduction of poverty. Energy poverty directly or indirectly affects the living standard of individuals in Ethiopia. The civilization of citizens is also measured with the use of modern technologies to make their lifestyle simple. The education system, health system, and agricultural system need to have sufficient electricity to improve the service delivery to individuals. Most of the population living in rural parts of Ethiopia uses firewood as an energy source, which brings deforestation, global warming, and health problem. The quality and distribution of education in rural Ethiopia are also affected by energy poverty. The energy poverty in Ethiopia is challenged by the pandemic COVID-19 in terms of education systems and sharing information about the pandemic disease to create awareness using online information sharing technology. Generally, poverty of energy significantly affects the rural area of Ethiopia as compared to urban areas. The government and private sectors of the country shall focus on renewable energy sources to minimize the effect of energy poverty on citizen lifestyle.

\section{Data Availability}

The data used to support the findings of this study are available from the corresponding author upon request.

\section{Conflicts of Interest}

The author declares no conflicts of interest.

\section{Supplementary Materials}

The supplementary material is the data filled in during the interviews about types of energy resources used by individuals living in the rural part of Ethiopia. In addition to the data collected by the central statistical agency of the country, direct interviews with 970 householders were done to know and check the real problem of energy in the society. Finally, the supplementary document includes the objectives of the survey: (a) to obtain good estimates on the type of energy consumption like firewood, fuels, electricity, and heat used in the rural and urban households; (b) to obtain information on the energy consuming appliances used in households. The objective of the survey was to collect reliable statistical information on the consumption of energy resources in households and to improve quality of the final energy consumption data in the overall energy balance of Ethiopia. The survey was carried out using interviews based on representative sample of households. (Supplementary Materials)

\section{References}

[1] IEA, Ethiopia Energy Outlook-Analysis, IEA, Paris, France, 2019.
[2] B. Bridge, "Individual and household-level effects of energy poverty on human development," Thesis, University of New Mexico, Albuquerque, NM, USA, 2015.

[3] A. Maxim, C. Mihai, C. M. Apostoaie, C. Popescu, C. Istrate, and I. Bostan, "Implications and measurement of energy poverty across the European Union," Sustain.vol. 8, no. 5, pp. 1-21, 2016.

[4] P. Dorosh and S. Rashid, Food and Agriculture in Ethiopia, IFPRI, Washington, DC, USA, 2012.

[5] D. H. Mazengia, "Ethiopian energy systems - potentials, opportunities and sustainable utilization," Thesis, Uppsala University, Uppsala, Sweden, 2010.

[6] "Ethiopia energy situation-energypedia," 2013, https:// energypedia.info/wiki/Ethiopia_Energy_Situation.

[7] J. Hou, Z. Tan, and X. Li, "Electricity consumption and economic growth in electricity demand forecasting," 2008.

[8] P. Frias, T. Gomez, and P. Linares, "Economic impact of 2020 renewable energy scenarios on the Spanish electricity market," in Proceedings of the 2010 7th International Conference on the European Energy Market, Madrid, Spain, June 2010.

[9] Y. Xu and C. Singh, "Distribution systems reliability and economic improvement with different electric energy storage control strategies," in Proceedings of the 2011 IEEE Power and Energy Society General Meeting, July 2011.

[10] F. M. Rubio and M. Robaina, "Economic impact of investments in the electricity sector - a hybrid general equilibrium and technological analysis," in Proceedings of the 2018 15th International Conference on the European Energy Market (EEM), Lodz, Poland, June 2018.

[11] A. Mouse, A. Miad, S. M. G. Mostafa, M. Azim, and Y. Arafat, "Feasibility analysis and economic impact assessment of microgrid renewable energy systems in Burao, Somaliland," in Proceedins of the 2019 1st International Conference on Advances in Science, Engineering and Robotics Technology (ICASERT), Dhaka, Bangladesh, May 2019.

[12] C. W. Njiru and S. C. Letema, "Energy poverty and its implication on standard of living in kirinyaga, Kenya," Journal of Energy, vol. 2018, Article ID 3196567, 12 pages, 2018.

[13] M. A. H. Mondal, E. Bryan, C. Ringler, D. Mekonnen, and M. Rosegrant, "Ethiopian energy status and demand scenarios: prospects to improve energy efficiency and mitigate GHG emissions," Energy, vol. 149, pp. 161-172, 2018.

[14] F. T. Maphosa, "The economic impact of renewable and nonrenewable energy technologies on small businesses: a case of small businesses near the Wallacedene taxi rank," in Proceedings of the 2018 International Conference on the Industrial and Commercial Use of Energy (ICUE), Cape Town, South Africa, August 2018.

[15] B. Sovacool and I. Vera, "Electricity and education: the benefits, barriers, and recommendations for achieving the electrification of primary and secondary schools," Energy Education, no. 12, pp. 1-36, 2014.

[16] S. Karekezi, S. McDade, B. Boardman, and J. Kimani, "Chapter 2: energy, poverty, and development," in Global Energy Assessment-Toward a Sustainable Future, pp. 151-190, Cambridge University Press, Cambridge, UK, 2012.

[17] S. Oum, "Energy poverty in the Lao PDR and its impacts on education and health," Energy Policy, vol. 132, pp. 247-253, 2019. 